University of Nebraska - Lincoln

DigitalCommons@University of Nebraska - Lincoln

Faculty Publications, Department of Psychology

Psychology, Department of

June 2000

\title{
Rural Youth: Ecological and Life Course Perspectives
}

Lisa J. Crockett

University of Nebraska-Lincoln, ecrockett1@unl.edu

Michael J. Shanahan

The Pennsylvania State University

Julia Jackson-Newsom

Tanglewood Research, Inc., Clemmons, NC

Follow this and additional works at: https://digitalcommons.unl.edu/psychfacpub

Part of the Psychiatry and Psychology Commons

Crockett, Lisa J.; Shanahan, Michael J.; and Jackson-Newsom, Julia , "Rural Youth: Ecological and Life Course Perspectives" (2000). Faculty Publications, Department of Psychology. 246.

https://digitalcommons.unl.edu/psychfacpub/246

This Article is brought to you for free and open access by the Psychology, Department of at DigitalCommons@University of Nebraska - Lincoln. It has been accepted for inclusion in Faculty Publications, Department of Psychology by an authorized administrator of DigitalCommons@University of Nebraska - Lincoln. 
Published in Adolescent Diversity in Ethnic, Economic, and Cultural Contexts: Advances in Adolescent Development, Volume 10, edited by Raymond Montemayor, Gerald R. Adams, and Thomas P. Gullotta. Thousand Oaks, CA: Sage Publications, 2000. Pages 43-74. Copyright (C) 2000 Sage Publications. Used by permission.

\title{
Rural Youth: Ecological and Life Course Perspectives
}

\author{
Lisa J. Crockett, University of Nebraska-Lincoln \\ Michael J. Shanahan, The Pennsylvania State University \\ Julia Jackson-Newsom, Tanglewood Research, Inc., Clemmons, NC
}

U ntil recently, rural youth were largely neglected within the sociological and psychological literature. Within sociology, there is a long and distinguished tradition of research on rural-urban differences (AdairToteff, 1995; Nelson, 1952), but typically these studies have focused on adults or on the rural population as a whole, with little attention to adolescents as an important subgroup. Conversely, within psychology, adolescents are recognized as a distinct developmental subgroup, but there has been little attempt to determine how and to what extent rural youth differ from their urban and suburban counterparts. From an ecological perspective (Bronfenbrenner, 1979; Ianni, 1989), differences would be expected, because rural settings differ from metropolitan settings in important ways, creating distinct contexts for development. Yet, few studies have focused on the distinctive features of the rural ecology and their implications for adolescent development.

In part, this neglect may reflect the perception that rural adolescents are few in number. However, a substantial percentage of U.S. adolescents are growing up in rural America. Data from the 1990 census indicate that rural youth (i.e., those who live in towns of fewer than 2,500 or unincorporated areas that are not near metropolitan areas) account for $15.5 \%$ of U.S. adolescents between the ages of 10 and 19; rural metropolitan youth (who live in small towns or outside incorporated areas but adjacent to a fairly large city) account for another 11.5\% (U.S. Census Bureau, 1992). 
Thus, more than one in four adolescents in the United States (almost 9.5 million youth) live in rural settings.

Inattention to rural youth also may reflect the perception that their problems are less pressing than those of inner-city and minority adolescents and that rural adolescents are insulated from the problems of contemporary urban America by virtue of their geographic isolation and strong ties to family and community. Indeed, traditional rural communities would appear to be high in social capital (see Coleman, 1988), defined as "social relationships that serve as resources for individuals to draw upon in implementing their goals" (Furstenberg, 1994, p. 5). Specifically, social capital depends on dense ties among family, kin, schools, religious institutions, and local community organizations. Such ties provide a framework of shared norms, mutual obligations, and access to information that supplements an individual's personal resources. Furthermore, communities rich in social capital are high in both investments in youth and in informal social control (Coleman, 1988), making them supportive environments for development. From this perspective, rural communities should promote adaptive functioning among adolescents. Yet, the sweeping social, economic, and demographic changes that have engulfed rural America define a context of risk for children and adolescents. During this century, technological advances, global competition, and spreading urbanization have transformed rural settings and ways of life radically. The number of jobs in farming and extractive industries has declined steadily since the early 1900s, eroding the traditional economic bases of rural communities (Freudenburg, 1992; Hobbs, 1994). More recently, the farm crisis of the early 1980s led to the loss of large numbers of family farms in the Midwest (Conger \& Elder, 1994).

These changes have brought increased disadvantage to run areas. Currently, poverty rates are higher in nonmetropolitan areas than in metropolitan areas (Jensen \& McLaughlin, 1995), especially among children (Hobbs, 1994), and unemployment is more common and more prolonged (Swaim, 1995). Moreover, rural-urban migration patterns have favored metropolitan areas strongly: Rural areas have witnessed large losses of the young, educated, and skilled (Lichter, McLaughlin, \& Cornwell, 1995), raising the specter increasing concentrations of poverty in some rural areas (Fitchen, 1995; Lichter, 1993). In small towns of fewer than 2,500 inhabitants, rapid depopulation and the growing concentration of elderly have been accompanied by precipitous declines in the availability of retail and professional services (Johansen, 1993). Models of social change suggest that such economic and demographic shifts disrupt traditional patterns of social organization, producing strain in the family and community (Conger \& Elder, 1994). In addition, economic decline and the out-migration of talented young adults conspire to reduce resources for schools and youth services (Hobbs, 1994). Thus, the social changes transforming rural America create challenges for successful adolescent development. In recognition of these and other problems, several reports published in the past few decades have identified rural children and youth as being "disadvantaged" or "at-risk" (e.g., Edington, 1970; Ehly \& Retish, 1990; Helge, 1990; William T. Grant Foundation, 1988).

A third reason for the lack of attention to rural adolescents may relate to the difficulties inherent in studying such a diverse group of youth. Although rural communities may share important characteristics that distinguish them from metropolitan communities, they also differ from each other along such potentially important dimensions as geographic region, ethnic composition, occupational structure, and access to major cities. Thus, life for adolescents in rural Mississippi is different from life for rural youth in the small mining towns of Pennsylvania or the farming communities of rural Iowa. Because of this diversity of settings, many of which have not yet been studied adequately, generalizations about rural youth at this point are difficult.

Despite the scientific challenges, the study of rural adolescents has much to contribute to the field of adolescence and to social policy. From a policy perspective, a focus on rural youth can identify areas of risk or disadvantage that call for intervention; it also can provide insight into the sources of resilience among rural youth that may apply in other settings as well. From a theoretical perspective, the study of rural adolescents can enhance our understanding of basic developmental and ecological processes. In particular, the confluence of social change and social capital in rural communities offers a unique opportunity to study both the challenges to healthy development created by social change and the dynamic processes of family and community adaptation.

Drawing on the themes of social change, ecological risk, and their implications for the life course, this chapter is intended as a point of de- 
parture for future research on rural adolescents. We begin by considering the basic but difficult issue of defining the ecology of rural youth, noting possible sources of risk and resilience. We then examine research on psychosocial adjustment among rural youth, identifying how they are advantaged and disadvantaged relative to other youth. Third, we turn to a central challenge facing contemporary rural youth: the need to reconcile attachments to family and place with a desire for educational and occupational mobility. Finally, we suggest conceptual and empirical guidelines for future research.

\section{Defining the Ecology of "Rural” Youth}

Rural typically has been defined comparatively, relative to the qualities of urban life. Within this comparative framework, some researchers have relied on a rural-urban dichotomy. The census criteria are illustrative of this approach: Since at least 1874, the census has defined rural residents as anyone living in or near towns of some specified size (e.g., fewer than 2,500 residents). The limitation of this approach is readily apparent: Even if the complexities of rural communities can be distilled into measurable dimensions, cutoff levels for dichotomous classifications are imprecise and inherently arbitrary. One example of this problem involves densely populated areas outside cities and towns. Under earlier census definitions, these unincorporated areas would be considered "rural"; yet, based on population density, these areas should be counted as "urban." In recognition of this problem, the census definition of "town" and "city" has been modified repeatedly to accommodate increasing population density within unincorporated areas (Truesdell, 1949).

A second comparative strategy assumes that, rather than representing an absolute dichotomy, rural and urban communities fall| along a continuum defined by multiple dimensions, such as population heterogeneity, size and density, and the predominance of agriculture (e.g., Sorokin \& Zimmerman, 1929; Wirth, 1938). Thus, the "purely rural" community is sparsely populated, lacking in diversity, and based on farming as a way of life and livelihood.

Problems also have arisen with this approach. First, rural-urban typologies reflect so many criteria that the validity of the distinction is questionable (Dewey, 1960). Second, empirical investigations have found that variables thought to underlie the rural-urban continuum are not always closely interrelated. For example, Willits and Bealer (1967) examined correlations among three dimensions of rurality: ecological (e.g., population density), occupational (e.g., proportion of farmers in the area), and sociocultural (prevalence of traditionalism in the area) and found that these relations were uniformly low. Such results are contrary to the notion of an underlying continuum. Indeed, Beers (1957) suggested that the rural-urban distinction, although initially valid, has become less meaningful during the 20th century as interstate highways and mass communication have strengthened the connection between rural and urban areas and as the predominance of agriculture has waned in rural areas. Similarly, Hobbs (1994) noted, "Cities have deconcentrated into the countryside, and rural and urban lifestyles have converged under the effects of a mass society with its mass media and mass consumption" (p. 149).

Nonetheless, people readily make use of the rural-urban distinction to characterize places and persons (Jacob \& Luloff, 1995). Thus, a third measurement strategy relies on an individual's perception of place. For example, based on interviews with a small group of Californians, Hummon (1986) reported that self-identified small-town residents defined themselves as coming from a place of more intimate bonds, domesticity, and tradition than city dwellers; they also rejected "spurious" urban values (e.g., materialism, conformity). "Country people," a popular self-designation of rural town residents, viewed themselves and their community as being independent, practical, plain, broadly skilled, and close to nature because of outdoor activities (see also Bell, 1992). This research suggests that, although the rural-urban distinction cannot be quantified easily, it remains an important social category and a basis for self-definition and community identity. As such, it may have important implications for the socialization of young people.

The preceding discussion alerts us to the challenges of defining "rural" and to the caveats one must keep in mind when interpreting empirical findings. Clearly, there is no consensus about how "rurality" should be defined and measured. Still, it can be argued that four dimensions-population size and density, community ties, traditionalism, and land use- have figured prominently in discussions of rural life and serve as a possible basis for defining rural settings. Importantly, these ecological dimensions also appear to have important implications for adolescent development. 
We turn next to a discussion of these four dimensions and their possible influences on rural youth.

\section{Population Size and Density}

Rural areas generally have been characterized by low population density and small community size. These demographic criteria may be important for adolescent adjustment because of their effects on social participation and psychological well-being. Barker has argued that "undermanned" settings, in which relatively few people are available to fill a large number of roles, require greater levels of participation by individuals in the system, $\mathrm{m}$ such settings, individuals are actively recruited to fill important roles. For example, Barker and Gump (1964) found that students from small schools participate in twice as many extracurricular activities as do those in large schools; they are also more likely to report feeling needed, responsible, and confident. Similarly, small communities may constitute undermanned settings in which adolescent participation is actively solicited. Rural adolescents may be highly involved in their schools and communities, with resulting psychological benefits.

Retrospective accounts of former graduates of small rural high schools in Iowa confirm some of the advantages of these educational settings (Schonert-Reichl, Elliott, \& Bills, 1995). Many graduates commented on the benefits of being involved in multiple extracurricular activities, including opportunities to assume leadership roles and to develop selfconfidence. Many also emphasized the personal attention they received from teachers.

Undermanned settings also may affect adolescent peer networks. Because of their greater levels of participation, rural adolescents may have a larger pool of familiar age-mates to draw on in forming smaller, intimate groups; they also may possess enhanced "people skills." In fact, several studies indicate that a larger percentage of rural adolescents are designated "popular" when compared with their urban counterparts, whereas fewer are rejected or neglected (Darling, Munsch, \& Foster-Clark, 1991). This finding supports the notion that rural youth are more likely to be known and liked by their peers.

On the other hand, because of the extensive connections found in rural peer networks, those rural adolescents who are rejected or neglected tend to be evaluated in these terms by a larger percentage of their associates, as was found by Darling et al. (1991):

Continuing contact between children in multiple settings will allow even children with low social impact to find a niche within the peer group. . . . Unfortunately, these same structural characteristics also increase the likelihood that individuals with strong negative characteristics will carry their reputation with them. (p. 6)

In line with this conclusion, a retrospective study of graduates of small rural high schools indicated that the choice of peer groups in high school was limited and that adolescents who were not mainstream were marginalized (Schonert-Reichl et al., 1995). Thus, population size and density may be important correlates of psychosocial adjustment because of their impact on peer networks.

A related consideration concerns the homogeneity of rural communities and rural schools. Recent studies indicate that urban settings are more culturally diverse, more tolerant of differences, and less conventional than rural settings (Fischer, 1995). Thus, rural settings may seem more constraining to adolescents who do not fit the conventional mold. In line with this notion, some graduates of small rural schools expressed dissatisfaction with the lack of diversity in their communities and with attitudes that they described as narrow-minded (Schonert-Reichl et al., 1995). Other graduates noted that there was insufficient emphasis in their schools on higher education and a limited awareness of career options; women, in particular, reported that schools did little to expand their knowledge of non-traditional jobs. Thus, the homogeneity of rural communities may limit adolescents' perceptions of educational and occupational opportunities and constrain the range of acceptable identities.

Finally, population size may be related to the levels of psychological distress felt by rural adolescents in times of social change. Hoyt, O'Donnell, and Mack (1995) argued that economic hardship has been particularly damaging to small rural communities (i.e., villages with fewer than 2,500 inhabitants) in terms of both regional structure and culture. Small communities lost much of their commercial base during the farm crisis of the 1980s, and this loss promoted out-migration of the young and educated. In turn, social services—hospitals, government offices, and schools—were 
consolidated, with the result that residents who remained had less immediate access to important resources. Consolidation and the resulting loss of local services contributed to feelings of isolation, dissatisfaction, and lower cohesion among the residents of small rural communities, although such distress was less evident in larger rural towns and among farmers. Hoyt et $\mathrm{al} / \mathrm{s}$ analysis of psychological distress by place size revealed that, after controlling for individual hardship and social and personal resources, persons living in smaller communities had significantly greater depressive symptoms. Thus, in the context of recent economic downturns, small population size maybe associated with increased psychological risk among rural adolescents.

\section{Community Ties}

Rural communities also have been characterized as places of dense social networks and strong community ties. Residents (smaller, rural places express both greater satisfaction with the communities than do residents of more densely populated areas (Hummon, 1992) and more regret at the prospect of leaving (Kasarda \& Janowitz, 1974). Smaller community size is also associated with greater life satisfaction among rural Appalachian young adults, as is proximity to one's childhood home (Wilson \& Peterson, 1988). Among adolescents, attachment to community may be fostered by strong intergenerational networks (Schneider \& Borman 1993); this can be seen in the reflections of one young adult:

My dream is to someday come back to the rural area and find a good steady job and raise my children. I miss the friendly people, being able to help one another out and knowing that if you need a helping hand there's someone there. In the small town I felt safe and loved, needed. I want my kids to grow up in a rural area like I did so they can go to the smaller school where the teachers are able to spend time with each individual. I want my kids to be part of a community that cares about each other and not just about themselves. (Schonert-Reichl \& Elliott, 1994, p. 8)

From a social capital perspective, the strong social network of rural communities constitute a potential resource. The dense social networks, homogeneity, and smaller populations of rural communities may increase the integration of adolescents into the community and also the consistency of socialization pressures, contributing to a sense of social responsibility and security. On the other hand, as noted previously, the resulting pressure toward conformity may be experienced by some adolescents as restrictive and narrow-minded.

\section{Traditionalism}

Rural traditionalism is thought to encompass lower materialism, greater cooperation, more conservative attitudes, and more traditional gender roles. Yet, the empirical support for this assumption is weak, in part because rural-urban comparisons are rare, and in part because the comparisons that do exist are inconsistent (Provorse, 1996). For example, several studies have demonstrated that the attitudes, beliefs, and values of rural residents are generally traditional and conservative (Fischer, 1975; Nelsen \& Yokley, 1970; Schnaiberg, 1970), but the accuracy of this conclusion has been questioned (e.g., Melton, 1983). Similarly, the assumption that rural residents are more religious than urban residents and hold more conservative religious beliefs has received some empirical support (e.g., McCartin \& Freehill, 1986; Meystedt, 1984), but the findings are inconsistent (Melton, 1983).

Rural-urban comparisons using adolescent samples are virtually nonexistent. Instead, a few researchers have compared farm residents with rural town dwellers. For example, drawing on a sample of rural Pennsylvania high school sophomores in 1959-1960, Willits and Bealer (1963) found a pattern of less conservatism among rural town youth as compared to farm youth or youth residing in open nonfarm country. Although this could be taken as evidence of greater traditionalism in less urban areas, the amount of variance accounted for by place of residence was quite small, indicating that, although statistically significant, such differences are substantively unimportant.

Research on gender roles has produced similarly equivocal results. Demographic studies show that rural women marry earlier than do women from metropolitan areas (e.g., McLaughlin, Lichter, \& Johnston, 1993), a pattern that could indicate greater endorsement of traditional gender roles among rural women but that also may reflect limited occupational opportunities for women. Furthermore, there is some evidence that ru- 
ral women are less likely to work outside the home than are urban women (Schnore, 1966) and that rural women who do work outside the home spend more time on housework than their urban counterparts (Lawrence, Draughn, Tasker, \& Wozniak, 1987).

Relatedly, research on children's household chores points to possible rural-urban differences in gender role socialization. White and Brinkerhoff (1981) examined the gender-typing of children's chores in a representative sample of families from Nebraska. A comparison of children and adolescents in farm, rural nonfarm, and urban families revealed that although rural nonfarm families were most likely to assign chores differentially based on gender, farm families were the least likely to do so; urban families fell in between. The authors speculate that when labor demands are high, the gender stereotyping of work becomes dysfunctional. Thus, the hypothesis of greater traditionalism in rural areas was supported for nonfarm families but not for farm families. To date, the premise of greater traditionalism in rural areas has not been well tested, and the results that are available provide only mixed support.

\section{Land Use and the Predominance of Agriculture}

Although agriculture was traditionally the dominant occupation in rural America, the number of jobs in agriculture has been declining consistently for more than a century, and other industries have come to predominate in many rural counties. Extractive industries, such as mining and logging, along with railroad employment, also are considered traditionally rural industries (Freudenberg, 1992). In recent decades, there has been increased diversification of rural land use as a function of declines in agricultural employment, the deconcentration of urban areas, and regional changes in economic opportunities (Hobbs, 1994). A recent classification system of nonmetropolitan counties includes seven designations: agricultural-dependent, manufacturing-dependent, mining-dependent, and government-dependent counties, along with federal lands, retirement destinations, and persistent poverty areas (Bender et al., 1985) The proportion of rural residents living in these various types $\mathrm{d}$ counties attests to the changing occupational profile of rural America: In 1990, 39\% of the nonmetropolitan population lived if manufacturing-dependent counties and $24 \%$ lived in retirement counties; only $14 \%$ lived in agricultural counties (U.S. Department of Agriculture, 1993).
Both occupational structure and demographic trends differ across these different types of counties. For example, during the 1980s, retirement counties increased in population largely as a result of in-migration of older adults, whereas farming-dependent counties had an overall loss of $10 \%$, due to out-migration of young adults and lower rates of births relative to deaths (Johnson, 1993). Even though both types of counties experienced an increase in the proportion of older people, the underlying process is different (influx of retirees from metropolitan areas vs. out-migration of young adults) and may have different implications for adolescent development (Hobbs, 1994).

Yet another dimension of ecological variation in rural counties concerns the proximity to a metropolitan area. Closeness to metropolitan areas expands the range of employment opportunities available to rural residents, making them less likely to relocate; it also increases the probability that metropolitan residents will move into the county. In turn, these trends influence population size and growth in the county (Johnson, 1993). Such regional and county differences underscore the importance of land use in shaping the local economy and ecology; they further attest to the diversity of rural settings with respect to population size, employment opportunities, poverty, and ethnic composition. As noted previously, such differences influence the community setting, creating diverse ecologies for adolescent development.

The picture that emerges from this discussion of rural settings is one of both developmental supports and constraints. The extensive ties within the peer group and throughout the rural community should provide ample social support and access to social capital for adolescents who can take advantage of them. On the other hand, youth who are unconventional or who have nontraditional aspirations may feel constrained by the pressure toward conformity arising from dense social networks; worse yet, they may feel excluded and marginalized. Thus, the effects of a rural upbringing may be different for youth with distinct individual characteristics: Conventionally oriented youth with good social skills may benefit considerably, as may adolescents who need a high degree of consistency and structure. Youth who do not fit the patterns endorsed by the local community, however, may fare more poorly. In addition, regional and county-level differences in economic and demographic profiles and in patterns of social change suggest that rural communities comprise a mul- 
tiplicity of ecological niches, each presenting distinct opportunities and challenges for developing youth.

\section{Patterns of Psychosocial Adjustment}

To the extent that rural settings provide a context for development that is distinct from urban settings, rural-nonrural differences in adolescent psychological, social, and behavioral patterns would be expected. Comparisons of rural and nonrural adolescents to date have pointed to several differences that have implications for the development of rural youth. Some of these represent a rural advantage (e.g., in terms of social capital), whereas others suggest that rural youth are at risk.

\section{Family and Kin Relationships}

Many hypotheses about the rural family and kin system have been advanced. For example, rural families are thought to be more traditional, more authoritarian, and more cohesive than urban families. Yet, very little empirical research has examined the distinctiveness of rural family life. Indeed, a large body of research suggests that family processes in rural settings are quite similar to those found in other ecologies. For example. Conger, Patterson, and Ge's (1995) study of families in central Iowa and urban Oregon demonstrated that the processes linking stressful life events to marital relations and parenting were similar in both samples.

However, research by Elder and his colleagues (e.g.. Elder \& Conger, 1999) has identified several distinctive features of Iowa farm families that distinguish them from other rural families and, potentially, from families in metropolitan settings. Of course, these distinctive features may not be typical of all rural farm families; yet, to the extent that the Iowa sample is demographically similar to many rural areas and insofar as farm families in other settings are also subject to economic fluctuations, these findings offer a reasonable basis for future study.

First, family relationships on the farm were found to be highly interdependent, because they were focused on the maintenance of the farm as a business and way of life (Elder \& Conger, 1999). For example, compared to nonfarm children, farm children spent considerably more time with their fathers, working and participating in community activities. Low-achieving adolescents from farm backgrounds (who are more likely to remain in the community and continue with farming) expressed greater levels of warmth toward their fathers and were more often sought out by their parents for advice. Thus, it appears that farm adolescents who plan to remain on the farm are more highly integrated in the family business and enjoy better relationships with parents.

Second, grandparents in farm families, especially paternal grandparents, were more involved in their adolescent grandchildren's lives than was true in nonfarm families (King \& Elder, 1995). Grandparents in farm families were more likely to participate in activities with their adolescent grandchildren and to serve as a companion, in large part because they lived closer to them. Whether these relationships promoted healthy development is difficult to determine, however, because most adolescents who had close and nurturant relationships with their grandparents also enjoyed better relationships with their parents. However, qualitative data indicated that grandparents act in a wide range of roles in farm families and were frequently evaluated in very positive terms (Elder \& Conger, 1999). This was especially true among the small groups of adolescents who had relatively poor relationships with their parents but lived close to a grandparent. Thus, there is evidence that grandparents may play a more important role in the lives of adolescents growing up on farms, with possible psychological benefits for adolescents, particularly those without close relationships with parents.

Third, families who lived on a farm or who had a farm background were more likely to have strong community ties (i.e., both parents had an established history of involvement in a diverse range of community organizations such as the PTA, church, and civic organizations) when compared with nonfarm families. Mekos and Elder (1996) argued that such ties facilitate development by bringing adolescents into a wider network of supportive adults and by promoting participation in youth activities that are valuable socialization experiences. In other words, extensive ties to the community should increase an adolescent's access to social capital. Mekos and Elder reported that adolescents growing up in families with strong community ties have better grades and are rated as more socially competent by teachers than are adolescents with weak 
ties, even when parents' education is statistically controlled. Thus, some evidence suggests that adolescents growing up in rural families with extensive community ties are more likely to succeed at the central tasks of adolescence.

Findings to date suggest that many of the presumed strengths of rural families, such as connections to extended family and involvement in a supportive community network, may be more characteristic of farm families. If so, adolescents in farm families may show greater resilience than nonfarm youth in times of social change.

\section{Productive Roles}

Although there is considerable interest in contemporary adolescent productive roles (Greenberger \& Steinberg, 1986; Mortimer, Finch, Ryu, Shanahan, \& Call, 1996; Steinberg \& Dornbusch, 1991), very little attention has been devoted to rural-nonrural differences in work experiences. Yet, historically, productive activities of the young represented an important path to adulthood (Modell, 1989), especially in rural settings (Zelizer, 1985). Recent research suggests that adolescent work contributes little to the economic well-being of contemporary urban families (Greenberger \& Steinberg, 1986; Mortimer et al., 1996), but both historical and contemporary records indicate the potentially substantial role of adolescents in the rural household economy (Bartlett, 1993; Friedmann, 1978).

Some adolescent rural work is thought unique for its involvement of extended kin and close family associates, its delegation of serious responsibilities, and its important consequences for the family. Drawing on his analysis of Depression-era cohorts. Elder (1974) reported that when adolescent work constitutes a genuine contribution to the family's well-being, personal maturity, self-conceptions, and relationships with parents are enhanced. Thus, rural work experience may offer greater psychological and interpersonal rewards than do other forms of adolescent work.

Indeed, studies that have compared urban with rural samples suggest large ecological differences in the meaning of work, often favoring the social development of rural youth. For example, in a series of studies, Shanahan, Elder, Burchinal, and Conger (1995, 1996a, 1996b) have shown that rural youth are more likely to work in response to family need. Al- though both urban and rural adolescents reported being employed for reasons of immediate gratification, more than half of all rural teenagers in the Iowa sample reported assuming additional chores and paid labor in response to family need. Also, rural adolescents were more likely to spend earnings in ways not immediately connected to their enjoyment. Among those reporting wages, roughly one third of rural 9th and 10th graders spent money on the family, compared to about $10 \%$ of youth in the urban sample.

Importantly, both earnings and nonleisure spending appeared to improve relationships with parents in the rural sample (Shanahan et al., 1996a, 1996b). Earnings and nonleisure spending were related to less parental monitoring, more sharing of advice within the family, and the affective quality of the relationship. Although nonleisure spending also improved parent-child relationships in the urban sample, there was some indication that too much nonleisure spending led to a deterioration of these relationships. Finally, rural, but not urban, earnings enhanced adolescents' self-efficacy (Shanahan et al., 1995).

Not all the rural-urban differences connoted advantages for rural youth, however. Some evidence suggests that involvement in chores leads to a decline in efficacy among farm boys, especially by mid-adolescence (Shanahan et al., 1995). This may reflect difficulties that adolescent farm boys who do not plan to become farmers have in disengaging from the family farm. Also, some rural work (especially chores) may involve an element of coercion and thus foster feelings of resentment and hostility between the generations. Thus, the evidence suggests that some but not all aspects of rural work are beneficial to adolescent social development; in particular, chores may entail some costs, especially for older farm boys.

\section{Achievement and Aspirations}

Educational attainment. National studies demonstrate a clear difference in educational attainment between rural and nonrural residents. In 1988, the average educational level of nonmetropolitan workers aged 18 to 64 was 12.7 years, as compared to a national average of 13.2 years (McGranahan \& Ghelfi, 1991). Relatedly, the high school drop-out rate is higher in rural areas than in metropolitan areas; for example, in 1985, 
the nonmetropolitan drop-out rate was $15.2 \%$, as compared to $13.9 \%$ in metropolitan areas (Swaim \& Teixera, 1991). In 1990, the drop-out rate among youth aged 16 to 24 was $13.6 \%$ in rural areas, $10.7 \%$ in suburban areas, and $17 \%$ in central cities (Lichter, Cornwell, \& Eggebeen, 1993). Thus, aggregate rural drop-out rates fell between suburban and central city rates.

Using 1990 census data, Lichter et al. (1993) examined family background variables that could help explain the rural-suburban difference in high school drop-out rates. For unmarried youth aged 16 to 18 living with parents, family structure variables, such as living with only one parent, being a parent oneself, and residing in a large household, all increased the likelihood of dropping out; however, these variables failed to account for the rural-suburban difference. In contrast, controlling family poverty status reduced the rural-suburban difference to nonsignificance, indicating that differential family poverty accounts for the differences in high school drop-out rates.

Although Lichter et al. (1993) could not address the mechanisms through which poverty affects the educational attainment of rural youth, other research has provided insight into these processes. In a small-scale study of 90 rural African American preadolescents aged 9 to 12, Brody, Stoneman, and Flor (1995) found that family financial resources were associated with more harmonious family interactions, which, in turn, were associated with better academic competence. In addition, financial resources were associated with self-regulation, which, in turn, predicted academic competence. Apart from its impact on family functioning, rural poverty may affect educational attainment by influencing educational aspirations or by undermining school quality.

Despite the legitimate concern over rural-urban differences in educational attainment, not all rural adolescents are at educational risk. For example, Schonert-Reichl et al. (1995) found that approximately $80 \%$ of their rural Iowa sample received some form of post-secondary education. Such findings highlight the diversity of rural youth and the need to consider the nature of the specific rural context when examining issues of developmental risk.

Educational and occupational aspirations. Studies have indicated consistently that the educational expectations of rural youth fall below those of nonrural adolescents (e.g., Cobb, McIntire, \& Pratt, 1989; Hansen \& McIntire, 1989; Sarigiani, Wilson, Petersen, \& Vicary, 1990), although the size of these differences may be small (Haller \& Virkler, 1993). Because educational aspirations influence educational attainment and, hence, social mobility, the lower aspirations of rural youth may represent a disadvantage meriting intervention (e.g., Breen, 1989; Cobb et al., 1989; Preble, Phillips, \& McGinley, 1989).

In part, the rural-nonrural discrepancy in educational aspirations reflects differences in family socioeconomic status (SES). The SES of rural families is, on average, somewhat lower than that of nonrural families (e.g., Swanson \& Butler, 1988), although, in part, this is due to the low occupational prestige scores associated with farming. Family SES, in turn, is positively associated with children's educational aspirations. In one study, about one third of the rural-nonrural difference in educational aspirations was explained by differences in family SES (Haller \& Virkler, 1993).

A second explanation for the rural-nonrural difference focuses on the occupational structure within rural areas. According to this perspective, rural economies are less diversified than urban ones and offer a restricted range of occupational opportunities (Reid, 1989). In particular, rural industries, which tend to involve agriculture or the extraction of raw materials (e.g., mining, forestry), primarily provide manual and service jobs. To the extent that adolescents' vocational aspirations are shaped by the jobs they see in their communities (Ianni, 1989), we would expect rural adolescents to aspire more to manual and service occupations than would be true of suburban and urban youth, who receive greater exposure to managerial and technical occupations (Haller \& Virkler, 1993). Furthermore, because traditional rural jobs require relatively little education, educational aspirations should be lower for rural youth than for nonrural adolescents.

In support of this structural explanation, several studies have shown that somewhat fewer rural than nonrural youth expect to hold professional and technical jobs (e.g., Cobb et al., 1989; Haller \& Virkler, 1993). In addition, slightly more rural than nonrural students expect to have a lower-level white-collar job or a blue-collar job at age 30 (Haller \& Virkler, 1993). Moreover, when both family SES and occupational aspirations are controlled, the initial difference in educational aspirations diminish- 
es considerably (Haller \& Virkler, 1993). Research on rural Appalachian high school students also supports the notion that limited economic opportunities are associated with lower educational ambitions (Schwarzweller, 1973).

At the same time, the rural-nonrural difference in educational aspirations is not exceedingly large. Drawing on the 1980 High School and Beyond data set, Haller and Virkler (1993) found an effect size for nonrural residence of only .23, amounting to one half point on a 9-point scale. Furthermore, the aspirations of rural youth are not uniformly low. In a national sample, $51 \%$ of rural seniors, as compared to $60 \%$ of nonrural youth, expected to attend at least some college (Haller \& Virkler, 1993). Studies of more circumscribed samples also have found that more than half of rural adolescents expect to go to college (e.g., Hektner, 1995). Regarding occupational aspirations, Haller and Virkler reported that 50\% of rural youth (vs. 59\% of nonrural youth) anticipated holding professional and technical jobs, whereas 34\% of rural youth (vs. 29\% of nonrural youth) expected to hold blue-collar or white-collar jobs at age 30 . These findings indicate that the aspirations of rural youth are not highly constrained, although they are somewhat lower than those of nonrural adolescents.

Research suggests that more recent cohorts of rural youth perceive a wider array of occupational options. A comparison of two ninth grade cohorts from the same high school in 1967 and 1979 indicated that the younger cohort was aware of many more occupations and viewed more of them as possible for themselves (Sundberg, Tyler, \& Poole, 1984). In the absence of a nonrural comparison group, it is impossible to determine whether this difference reflected an increasing awareness of vocations among rural youth relative to nonrural youth (i.e., a catch-up effect) or a general cohort-related increase. It seems plausible, however, that the spread of urbanization and mass communication, as well as local concerns about the more limited aspirations of rural youth, would lead to an increment in occupational awareness among rural adolescents.

\section{Health and Well-Being}

Psychological well-being. Rural-nonrural comparisons of specific psychological dimensions yield somewhat equivocal findings. Several studies have examined differences in self-image, producing mixed results.
Trowbridge, Trowbridge, and Trowbridge (1972) reported that rural children in the third through eighth grades had higher self-image than did nonrural children. Prendergrast, Zdep, and Sepulveda (1974), however, found no differences in self-image between rural and nonrural girls aged 9 through 17. More recent studies found that rural adolescents have lower self-image than do their nonrural counterparts (Petersen, Offer, \& Kaplan, 1979; Sarigiani et al., 1990).

There is also some suggestion that rural adolescents have more psychological symptoms than do nonrural youth. Both Petersen et al. (1979) and Sarigiani et al. (1990) found that rural youth score lower on emotional tone, a measure assessing positive psychological functioning and an absence of depression and anxiety. Similarly, Helge (1990) reported higher rates of depression for rural secondary school students than for their urban and suburban counterparts. As with metropolitan adolescents, depression in rural adolescents is related to family financial stress (ClarkLempers, Lempers, \& Netusil, 1990; Simons, Whitbeck, \& Wu, 1994). Given that poverty rates are higher in rural areas than in nonrural areas, depression may be of particular concern for rural adolescents.

Drug and alcohol use. Though once thought to be a problem primarily in urban areas, recent data reveal that alcohol and drug use among adolescents is now a cause for concern in rural areas, as well. According to the 1993 data from the Monitoring the Future Study (Johnston, O'Malley, \& Bachman, 1994), only small differences in alcohol and drug use now exist between adolescents in metropolitan and nonmetropolitan areas. Although more rapid increases in the use of drugs and alcohol in metropolitan areas during the late 1970s produced higher rates of use in urban areas, recent declines in metropolitan drug use have reduced these differences significantly.

Rates of alcohol use are similar for nonmetropolitan and metropolitan youth. Among 12th graders, the 30-day prevalence of alcohol use in 1993 was $51.9 \%$ in nonmetropolitan areas, as compared to $52.3 \%$ in large metropolitan areas and $49.8 \%$ in other metropolitan areas (Johnston et al., 1994). A similar pattern is found for lifetime prevalence, with 12th graders from nonmetropolitan areas reporting rates of alcohol use nearly identical to those in metropolitan areas $(86.8 \%, 88.0 \%$, and $86.7 \%$, for rural, large metropolitan, and other metropolitan areas, respectively). Howev- 
er, youth in nonmetropolitan areas report slightly higher rates of binge drinking than do those in metropolitan areas $(32.0 \%$, as compared to $29.9 \%$ and $26.4 \%$ for large and other metropolitan areas, respectively).

In contrast, marijuana use is somewhat lower among rural adolescents as compared to metropolitan adolescents. In 1993, the 30-day prevalence of marijuana use for 12 th graders was $13.8 \%$ for nonmetropolitan areas, $15.3 \%$ for other metropolitan areas, and $18.0 \%$ for large metropolitan areas (Johnston et al., 1994). The lifetime prevalence of use showed similar patterns: $32.7 \%$ for nonmetropolitan areas, $36.3 \%$ for other metropolitan areas, and $36.5 \%$ for large metropolitan areas. Use of other illicit drugs is low and similar for nonmetropolitan and metropolitan youth.

Another area of concern, particularly for rural youth, is tobacco use. Nonmetropolitan and metropolitan youth are equally likely to use cigarettes $(30.3 \%, 29.8 \%$, and $29.5 \%$, for nonmetropolitan, other metropolitan, and large metropolitan areas, respectively; Johnston et al., 1994). However, rural youth are much more likely to use smokeless tobacco than youth from metropolitan areas (15.0\%, as compared to $9.9 \%$ and $7.1 \%$ for other and large metropolitan areas, respectively).

The correlates of drug use are similar for rural and nonrural adolescents. In a review of the literature on rural adolescent alcohol and drug use, Donnermeyer (1992) found that risk factors for rural adolescent drug and alcohol use are similar to those identified for nonrural and nationally representative samples (e.g., age, gender, ethnicity, academic performance, attachment to school, religion, quality of relationship with parents, parental monitoring, and peer use). Although it is clear that adolescent substance use is a problem in both rural and nonrural areas, there are issues related to this trend that are unique to rural youth. Leukefeld, Clayton, and Myers (1992) suggested that problems with transportation, availability of services, and rural-urban differences in help-seeking behavior may have implications for the treatment of alcohol and drug use for rural adolescents. For example, many rural communities do not have primary prevention programs due to a lack of financial resources and personnel, problems that have been exacerbated by the ongoing demographic changes in rural areas. Thus, rural youth may have less access to preventive services than do nonrural youth. In addition, research on mental health service utilization suggests that rural residents are less likely to seek help than are residents of nonrural areas, controlling for levels of psychiatric disturbance (Kelleher, Taylor, \& Rickert, 1992). Possible explanations for this difference include cultural norms favoring self-reliance; concerns about confidentiality in close-knit communities; and distrust of physicians and social service agencies, who may be viewed as "outsiders" (Bushy, 1994; Kelleher et al., 1992). Similar considerations may keep rural adolescents from seeking treatment for drug-related problems.

\section{Turning Points in the}

Rural Life Course

Adolescence is the period when young people make decisions that will shape their adult life course. Many of these decisions revolve around educational and occupational goals, two key areas of planning for adolescents in modem societies (Nurmi, 1991). Others involve expectations concerning future family goals. What distinguishes rural youth is the need to consider where these goals can best be realized: in the community of origin or elsewhere. The limited occupational structure of rural communities and the ongoing economic decline in many rural areas have increased the salience of this issue.

\section{Transition to Adulthood}

One important question concerns the timing and nature of the transition to adulthood. Because of lower family SES and lower educational aspirations, rural youth may anticipate an accelerated transition into adult roles compared to metropolitan youth. Preliminary examination of this issue has supported this proposition. Bingham, Crockett, Stemmler, and Petersen (1994) compared a sample of rural youth with a sample of suburban youth in terms of their anticipated ages at reaching several young adult milestones: finishing their education, entering the workforce, marrying, and becoming a parent. In each case, the rural sample anticipated a significantly earlier transition to adult status. In part, the difference was a function of differences in family SES; however, controlling parents' educational attainment did not fully account for the difference. Additional analyses of the same rural sample indicated that the anticipated timing of adult role transitions was related to school performance and adoles- 
cent educational aspirations for both genders but also to family structure and traditional gender role attitudes for boys and to parental educational attainment, family relationships, and problem behavior for girls (Crockett \& Bingham, 1996). Whether these variables also can explain the rural-suburban differences in the expected timing of role transitions has yet to be determined.

\section{Residential Plans}

As noted previously, many rural young adults leave their home communities to seek educational and employment opportunities. During the 1980s, nonmetropolitan areas experienced a net loss of approximately 1.5 million young people (Hobbs, 1994; see also Fugitt, Brown, \& Beale, 1989). Even during the 1970 s, when migration into rural areas temporarily increased, talented rural youth continued to show high rates of outmigration (Rudkin, Elder, \& Conger, 1994). Studies of migrants from rural areas suggest that migration is often advantageous. Although the success of out-migrants may be due in part to selection factors (migrants tend to be better educated and more highly skilled), recent research suggests that rural out-migration confers benefits even for the poor and disadvantaged. Wenk and Hardesty (1993) found that poor rural men who migrated found work more quickly than did those who stayed in their rural communities, and poor rural women who migrated were less likely to remain in poverty. Thus, migration is not only a rational strategy for many rural youth but one that has important implications for the subsequent life course. Residential decisions are thus of critical importance for rural youth.

Yet, such decisions may be difficult, because realizing educational and vocational goals often means leaving one's family and home community; in this respect, the desire for social mobility is in conflict with attachments to family and place. Staying or leaving also may represent a choice between a traditional lifestyle and a more "modern" one. Donaldson (1986) casts the decision to stay or leave as involving a tension between the "native culture" and becoming part of the American mainstream (p. 121).

Several studies provide evidence of this residential dilemma among rural youth. Drawing on interviews with youth residing in a village in Maine in the mid-1970s, Donaldson (1986) reported that remaining in the village was important to all of them and that "for most, a central theme was the attempt to reconcile attachments to community and past with a desire-or economic need - to be a part of the modem American mainstream" (p. 122). In a retrospective study of former high school students from small rural schools in Iowa, Schonert-Reichl and Elliott (1994) also found evidence of a residential conflict among their participants: Many young adults expressed the desire to return to a rural way of life but felt that their economic futures were tied to metropolitan areas. Finally, a study of ninth graders from rural Iowa revealed that one third of the sample reported both a desire to live near their parents and intentions to live elsewhere after completing their schooling - clearly conflicting goals (Elder, King, \& Conger, 1996).

In the only comparative study of this residential dilemma, Hektner (1995) compared adolescents from rural, urban, and suburban sites in Illinois. Rural youth were more likely to experience conflict, defined as a dual desire to live close to parents and relatives and to "get away from this area of the country," than were urban or suburban adolescents, but the difference was significant only for male youth and only among 10 th graders (not among 8 th or 12 th graders). At 10 th grade, more than half the rural adolescents held conflicting desires, as compared to just less than $40 \%$ of nonrural youth. Thus, the conflict was more prevalent among rural youth, but it was also experienced by adolescents from other settings.

Several researchers have suggested that the conflict between residential preferences and occupational aspirations may be stressful for rural youth (Sarigiani et al., 1990; Schonert-Reichl \& Elliott, 1994). Research on this issue is sparse, however, and provides mixed support for this notion. Hektner (1995) finds that rural students and those with conflicting residential desires are significantly more likely to report feelings of anger and emptiness. Similarly, Elder et al. (1996) report that Iowa students who have conflicting goals (i.e., a desire to remain close to family but an intent to settle elsewhere) express marginally higher depression and unhappiness than do students who plan to stay in their home communities. However, their depression is not significantly higher than that of unconflicted students who plan to relocate; in fact, only the two unconflicted groups differ significantly. Thus, in the Iowa sample, the intention to leave per se, rather than conflict between community-family attachments and the desire to relocate, is associated with greater psychological vulnerability. 
Whether or not the dilemma jeopardizes psychological well-being, the tension between community attachment and occupational goals appears to affect the choices of rural youth. Some youth may reduce their educational and occupational aspirations, bringing them into line with realistic employment prospects within their home community. For those who do leave the community, there is some evidence that appreciation of the rural community influences later residential choices. Schonert-Reichl and Elliott (1996) found that many of their young adult participants effected a compromise between the competing pulls of career and rural living by residing in rural communities and commuting considerable distances to their jobs in metropolitan areas. This allowed them to have the best of both worlds: to pursue their chosen careers and still live and raise their children in a more rural setting. These findings support the presence of the tension described by Donaldson (1986) and Hektner (1995) and also indicate that an appreciation of rural living (if not attachment to a particular rural community) affects the residential decisions of some youth with rural backgrounds.

\section{Future Directions in the Study of Rural Youth}

The preceding discussion raises several issues that need to be addressed in future research with rural youth. One key issue is the diversity among rural communities. Although generalizations about rural youth may have been possible when rural America was largely agrarian, they are far less valid today, given the diversification of land use in rural areas and accompanying differences in economic and demographic trends. Regional differences, which in part reflect variation in ethnic and racial composition, also may contribute to ecological diversity in rural settings, as do differences in poverty levels and proximity to metropolitan areas. In light of community differences, research on carefully defined local samples is needed, along with research on nationally representative samples that examines regional and county-level differences (MacBrayne, 1987).

In addition, there are important within-community differences that have implications for adolescent development. A clear example is the farm-nonfarm distinction. Elder and his colleagues identified differenc- es between farm families and nonfarm families in adolescents' relationships to fathers and grandparents, in work patterns, and in community involvement. Taken together, these findings underscore the uniqueness of farm families as contexts for adolescent development. More broadly, distinct family ecologies set the stage for distinct life course trajectories. Such family differences, as well as individual characteristics, need to be taken into account in future research. In accordance with an ecological perspective (Bronfenbrenner, 1979), rural youth must be viewed through a more differentiated lens that is sensitive to regional, county, community, and family-level differences and their potential influences on development. General patterns may emerge after systematic study but cannot be presumed a priori.

Second, any distinctive features of rural life need to be documented carefully, through rural-nonrural comparisons. Currently, there is surprisingly little research supporting some of our most basic assumptions about rural life: those related to family life, community cohesion, and traditionalism. Given the argument that rural-urban differences have dwindled under the effects of mass society (Hobbs, 1994), it is critical to document the size and consistency of remaining rural-nonrural differences. Moreover, given that rural-urban differences may partly reflect differences in ethnic composition and SES, such confounding factors must be taken into account.

Third, notions of risk, resilience, and social capital also should be applied in a more refined way. Rather than arguing that rural adolescents in the aggregate are disadvantaged or advantaged relative to nonrural youth, more careful attention should be paid to the sources of risk in particular rural populations and to the types of protective strategies that could be applied to foster positive outcomes. Clearly, some rural youth are at risk: those living in poverty, those with abusive parents, those exposed to marital conflict, and possibly those who deviate from community norms. Similarly, mitigating factors such as close family relationships and community support are not evenly distributed across rural America. For instance, the presumed benefits of rural families and rural communities may be concentrated in certain kinds of families (e.g., farm families) or in certain kinds of communities. Determining which rural youth are at risk and which youth have access to important family and community resources (e.g., social support, social capital) would be a logical first step in devel- 
oping a more differentiated perspective on rural risk and resilience. Risk usually is assessed in terms of individual and family characteristics but could be assessed at the community level, in terms of the amount and severity of dislocation brought about by social change. Similarly, the operation of social capital in rural communities has only begun to be explored and remains a rich area for future research.

\section{Conclusions}

Long-term trends of social change involving economic reorganization and migration continue to characterize rural life. In this context, there is an urgent need for the study of rural youth as they negotiate pathways into adulthood. At the same time, rural America often is viewed as a place rich in capital, including a heightened sense of individualism and self-reliance but also a sense of commitment to community and public life (Dalecki \& Coughenour, 1992).

This interplay of social change and social capital serves as a useful frame for analysis and may contribute to a more basic understanding of youth, ecological context, and the life course. What are the sources of vulnerability and risk found in rural settings? What are the distinct processes that detract from adolescent psychosocial adjustment, as reflected in the emergence of competence, health and well-being, and the transition into adult roles? It may be that young people figure more prominently in rural places by way of their extensive involvements in school, extracurricular activities, and unique work roles. In turn, they may be more highly integrated into adult social networks and engaged in activities that involve less role segmentation. However, there is very little research on ecological differences in the availability of social capital.

As our chapter suggests, there is considerable diversity in rural areas. Much of this diversity is related to varied patterns of land use. In turn, economic diversity in rural areas has coincided with new and often complicated patterns of work in the rural household: Mothers and fathers engage in combinations involving farming, light manufacturing, and graycollar work; rural residents commute to white-collar jobs in metropolitan areas. The complexities of the contemporary rural landscape and the ongoing economic and demographic changes in rural areas raise the challenges inherent in studying changing persons in changing contexts. Yet, the rewards of this endeavor are likely to be rich, contributing to our understanding of the diversity of youth in time and place.

\section{REFERENCES}

Adair-Toteff, C. (1995). Ferdinand Tönnies: Utopian visionary. Sociological Theory, 13, 58-65.

Barker, R. G., \& Gump, P. V. (1964). Big school-small school, high school size and student behavior. Stanford, CA: Stanford University Press.

Bartlett, P. F. (1993). American dreams, rural realities: Farm families in crisis. Chapel Hill, NC: University of North Carolina Press.

Beers, H. W. (1957). The rural community. In Review of sociology: Analysis of a decade (pp. 186-220). New York: John Wiley.

Bell, M. M. (1992). The fruit of the difference: The rural-urban continuum as a system of identity. Rural Sociology, 57(1), 65-82.

Bender, L. D., Green, B. I., Hady, T. F., Kuehn, J. A., Nelson, M. K., Perkinson, I. B., \& Ross, P. J. (1985). The diverse social and economic structure of non-metropolitan America. (Rural Development Research Rep. No. 49). Washington, DC: U.S. Department of Agriculture, Economic Research Service.

Bingham, C. R., Crockett, L. J., Stemmler, M., \& Petersen, A. C. (1994). Communi ty differences in adolescents' expectations about the transition to adulthood. Unpublished manuscript.

Breen, D. T. (1989). Enhancing student aspirations: A goal for comprehensive developmental guidance programs. Research in Rural Education, 6, 35-38.

Brody, G. H., Stoneman, Z., \& Flor, D. (1995). Linking family processes and academic competence among rural African American youths. Journal of Marriage and the Family, 57, 567-579.

Bronfenbrenner, U. (1979). The ecology of human development: Experiments by nature and design. Cambridge, MA: Harvard University Press.

Bushy, A. (1994). Implementing primary prevention programs for adolescents in rural environments. Journal of Primary Prevention, 14, 209-229.

Clark-Lempers, D. S., Lempers, J. D., \& Netusil, A. J. (1990). Family financial stress, parental support, and young adolescents' academic achievement and depressive symptoms. Journal of Early Adolescence, 10(1), 21-36.

Cobb, R. A., McIntire, W. G., \& Pratt, P. A. (1989). Vocational and educational aspirations of high school students: A problem for rural America. Journal of Research on Ru ral Education, 6(2), 11-16.

Coleman, J. S. (1988). Social capital in the creation of human capital. American Journal of Sociology, 94, 95-120.

Conger, R. D., \& Elder, G. H. (1994). Families in troubled times: Adapting to change in rural America. Hawthorne, NY: Aldine de Gruyter.

Conger, R. D., Patterson G., \& Ge, X. (1995). It takes two to replicate: A mediational model for the impact of parents' stress on adolescent adjustment. Child Development, 66, 80-97. 
Crockett, L. J., \& Bingham, C. R. (1996, March). Anticipating adulthood: The impact of family ecology and adolescent behavior on the expected timing of adult role transitions. Paper presented at the biennial meeting of the Society for Research on Adolescence, Boston.

Dalecki, M. G, \& Coughenour, C. M. (1992). Agrarianism in American society. Rural Sociology, 57, 48-64.

Darling, N., Munsch, J., \& Foster-Clark, F. S. (1991). Functional characteristics of the social networks of more and less competent early adolescents. Paper presented at the Hartman Conference on Children and Their Families, New London, CT.

Dewey, R. (1960). The rural-urban continuum: Real but relatively unimportant. American Journal of Sociology, 66, 60-66.

Donaldson, G. A. (1986). Do you need to leave home to grow up? The rural adolescents' dilemma. Research on Rural Education, 3(3), 121-125.

Donnermeyer, J. F. (1992). The use of alcohol, marijuana, and hard drugs by rural adolescents: A review of recent research. Drugs and Society, 7(1-2), 31-75.

Edington, E. E. (1970). Disadvantaged rural youth. Review of Educational Research, 40, 69-85.

Ehly, S. \& Retish, P. (1990). Children at risk: A review of the literature. Des Moines: FINE Foundation. University of Iowa.

Elder, G. H., Jr. (1974). Children of the Great Depression: Social change and life experience. Chicago: University of Chicago Press.

Elder, G. H., \& Conger, R. D., in collaboration with Russell, S. T., Shanahan, M. J., Mekos, D., King, V., \& Matthews, L. S. (1996). New worlds, new lives: Rural generation at century's end. Chicago: Univ. of Chicago Press.

Elder, G. H., King, V., \& Conger, R. D. (1996). Attachment to place and migration prospects: A developmental perspective. Journal of Research on Adolescence 6, 397-423.

Fischer, C. S. (1975). The effect of urban life on traditional values. Social Forces, 53, $420-432$.

Fischer, C. S. (1995). The subcultural theory of urbanism: A twentieth-year assessment. American Journal of Sociology, 101, 543-577.

Fitchen, J. M. (1995). Spatial redistribution of poverty through migration of poor people to depressed rural communities. Rural Sociology, 60, 181-201.

Freudenburg, W. R. (1992). Addictive economies: Extractive industries and vulnerable localities in a changing world economy. Rural Sociology, 57, 305-332.

Friedmann, H. (1978). World market, state, and family farm: Social bases of household production in an era of wage labor. Comparative Studies in Society and History, 20, 545-586.

Fugitt, G. V., Brown, D. L., \& Beale, C. L. (1989). Rural and small town America. New York: Russell Sage Foundation.

Furstenberg, F. F. (1994, November). The influence of neighborhoods on children's development. A theoretical perspective and research agenda. Paper presented at the Indicators of Children's Well-Being conference, Bethesda, MD.

Greenberger, E., \& Steinberg, L. D. (1986). When teenagers work: The psychological and social costs of adolescent employment. New York: Basic Books.

Haller, E. J., \& Virkler, S. J. (1993). Another look at rural-nonrural differences in students' educational aspirations. Journal of Research in Rural Education, 9(3), 170-178.
Hansen, T. D., \& McIntire, W. G. (1989). Family structure variables as predictors of educational and vocational aspirations of high school seniors. Research in Rural Education, 6, 39-50.

Hektner, J. M. (1995). When moving up implies moving out: Rural adolescent conflict in the transition to adulthood. Journal of Research in Rural Education, 11(1), 3-14.

Helge, D. (1990). A national study regarding at-risk students. National Rural Development Institute, Woodring College of Education, Western Washington University, Bellingham, WA.

Hobbs, D. (1994). Demographic trends in nonmetropolitan America. Journal of Research in Rural Education, 10(3), 149-160.

Hoyt, D. R., O’Donnell, D., \& Mack, K. Y. (1995). Psychological distress and size of place: The epidemiology of rural economic stress. Rural Sociology, 60, 707-720.

Hummon, D. M. (1986). City mouse, country mouse: The persistence of community identity. Qualitative Sociology, 9, 3-25.

Hummon, D. M. (1992). Community attachment: Local sentiment and sense of place. In I. Altman \& S. M. Low (Eds.), Place attachment (pp. 253-278). New York: Plenum.

Ianni, F. A. (1989). The search for structure: A report on American youth today. New York: Free Press.

Jacob, S., \& Luloff, A. E. (1995). Exploring the meaning of rural through cognitive maps. Rural Sociology, 60, 260-273.

Jensen, L., \& McLaughlin, D. K. (1995). Human capital and nonmetropolitan poverty In L. J. Beaulieu \& D. Mulkey (Eds.), Investing in people: The human capital needs of rural America (pp. 111-138). Boulder, CO: Westview.

Johansen, H. E. (1993). The small town in urbanized society. In D. L. Brown, D. Field, \& J. J. Zuiches (Eds.), The demography of rural life (pp. 58-82). University Park, PA: Northeast Regional Center for Rural Development.

Johnson, K. M. (1993). Demographic change in nonmetropolitan America, 1980-1990. Rural Sociology, 58(3), 347-365.

Johnston, L. D., O’Malley, P. M., \& Bachman, J. G. (1994). Drug use among American high school students: National trends through 1993. Rockville, MD: National Institute of Drug Abuse.

Kasarda, J. D., \& Janowitz, M. (1974). Community attachment in mass society. American Sociological Review, 39, 328-339.

Kelleher, K. J., Taylor, J. L., \& Rickert, V. I. (1992). Mental health services for rural children and adolescents. Clinical Psychology Review, 12, 841-852.

King, V., \& Elder, G. H., Jr. (1995). American children view their grandparents; Linked lives across three rural generations. Rural Sociology, 57, 165-178.

Lawrence, F. C., Draughn, P. S., Tasker, G. E., \& Wozniak, P. H. (1987). Sex differences in household labor time: A comparison of rural and urban couples. Sex Roles, 17 489-502.

Leukefeld, C. G., Clayton, R. B., \& Myers, J. A. (1992). Rural drug and alcohol treatment. Drugs and Society, 7(1-2), 95-116.

Lichter, D. T. (1993). Migration, population redistribution, and the new spatial inequality. In D. L. Brown, D. Field, \& J. J. Zuiches (Eds.), The demography of rural life (pp. 19-46). University Park, PA: Northeast Regional Center for Rural Development. 
Lichter, D. T., Cornwell, G. T., \& Eggebeen, D. J. (1993). Harvesting human capital: Family structure and education among rural youth. Rural Sociology, 58(1), 53-75.

Lichter, D. T., McLaughlin, D. K., \& Cornwell, G. T. (1995). Migration and the loss of human resources in rural areas. In L. J. Beaulieu \& D. Mulkey (Eds.), Investing in people: The human capital needs of rural America (pp. 235-256). Boulder, CO: Westview.

MacBrayne, P. (1987). Educational and occupational aspirations of rural youth: A review of the literature. Research on Rural Education, 4, 135-141.

McCartin, R., \& Freehill, M. (1986). Values of early adolescents compared by type of school. Journal of Early Adolescence, 6, 369-380.

McGranahan, D. A., \& Ghelfi, L. M. (1991). The education crisis and rural stagnation in the 1980s. In Education and rural economic development: Strategies for the 1990s (Economic Research Service, Staff Report No. AGES 9153, pp. 40-92). Washington, DC U.S. Department of Agriculture, Agriculture and Rural Economy Division.

McLaughlin, D. K., Lichter, D. T., \& Johnston, G. M. (1993). Some women marry young: Transitions to first marriage in metropolitan and nonmetropolitan areas. Journal of Marriage and the Family, 55, 827-838.

Mekos, D., \& Elder, G. H. (1996, March). Community ties and the development of competence in rural youth. Paper presented at the biennial meeting of the Society for Research in Adolescence, Boston.

Melton, G. B. (1983). Ruralness as a psychological construct. In A. W. Childs \& G. B. Melton (Eds.), Rural psychology (pp. 1-13). New York: Plenum.

Meystedt, D. M. (1984). Religion and the rural population: Implications for social work. Social Casework, 65, 219-226.

Modell, J. (1989). Into one's own: From youth to adulthood in the United States 1920-1975. Berkeley: University of California Press.

Mortimer, J. T., Finch, M. D., Ryu, S., Shanahan, M. J., \& Call, K. T. (1996). Work experiences, mental health, and behavioral adjustment: New evidence from a prospective study. Child Development, 67, 1243-1261.

Nelsen, H. M., \& Yokley, R. T. (1970). Civil rights attitudes of rural and urban Presbyterians. Rural Sociology, 35, 161-174.

Nelson, L. (1952). Rural sociology. New York: American Books.

Nurmi, J. E. (1991). How do adolescents see their future? A review of the development of future orientation and planning. Developmental Review, 11, 1-59.

Petersen, A. C., Offer, D., \& Kaplan, E. (1979). The self-image of rural adolescent girls. In M. Sugar (Ed.), Female adolescent development (pp. 141-155). New York: Brunner/Mazel.

Preble, B., Phillips, P., \& McGinley, H. (1989). Maine’s aspirations movement: Reaching out to youth. Research in Rural Education, 6, 35-38.

Prendergrast, P., Zdep, S. M., \& Sepulveda, P. (1974). Self-image among a national probability sample of girls. Child Study Journal, 4, 103-114.

Provorse, D. (1996). The search for the rural mindset: An empirical comparison of alternative definitions of reality. Unpublished doctoral dissertation. University of Nebraska-Lincoln, Lincoln, Nebraska.

Reid, J. N. (1989). The rural economy and rural youth: Challenges for the future. Journal of Research in Rural Education, 6(2), 17-23.
Rudkin, L., Elder, G. H., \& Conger, R. (1994). Influences on the migration intentions of rural adolescents. Sociological Studies of Children, 6, 87-106.

Sarigiani, P. A., Wilson, J. L., Petersen, A. C, \& Vicary, J. R. (1990). Self-image and educational plans of adolescents from two contrasting communities. Journal of Early Adolescence, 10, 37-55.

Schnaiberg, A. (1970). Rural-urban residence and modernism. Demography, 7, 71-85.

Schneider, B. \& Borman, K. (1993, April). Thinking about the future: Adolescents in a small town. Paper presented at the annual meeting of the American Educational Research Association, Atlanta, GA.

Schnore, L. (1966). The rural-urban variable: An urbanite's perspective. Rural Sociology 31, 131-143.

Schonert-Reichl, K. A., \& Elliott, J. P. (1994, February). Rural pathways: Stability and change during the transition to young adulthood. Paper presented at the meeting of the Society for Research on Adolescence, San Diego, CA.

Schonert-Reichl, K. A., \& Elliott, J. P. (1996, March). "There's no place like home:” A longitudinal investigation of rural adolescents' efforts to recreate their rural communities during adulthood. Paper presented at the biennial meeting of the Society for Research in Adolescence, Boston.

Schonert-Reichl, K. A., Elliott, J. P., \& Bills, D. B. (1995, April). "I feel that a rural education is a wonderful thing": Rural school students' narratives of their rural school education ten years after high school graduation. Paper presented at the annual meeting of the American Educational Research Association, New Orleans, LA.

Schwarzweller, H. K. (1973). Regional variations in the educational plans of rural youth: Norway, Germany and the United States. Rural Sociology, 38(2), 139-158.

Shanahan, M. J., Elder, G. H., Jr., Burchinal, M., \& Conger, R. D. (1995, April). Ecological patterns in adolescent productive activities: Predictors of involvement and consequences for self-identity. Paper presented at the biennial meetings of the Society for Research in Child Development, Indianapolis, IN.

Shanahan, M. J., Elder, G. H., Jr., Burchinal, M., \& Conger, R. D. (1996a). Adolescent earnings and relationships with parents: The work-family nexus in urban and rural ecologies. In J. T. Mortimer \& M. D. Finch (Eds.), Adolescents, work, and family: An intergenerational, developmental analysis (pp. 97-128). Newbury Park, CA: Sage.

Shanahan, M. J., Elder, G. H., Jr., Burchinal, M., \& Conger, R. D. (1996b). Adolescent paid labor and relationships with parents: Early work-family linkages. Child Development, 67, 2183-2200.

Simons, R. L, Whitbeck, L. B., \& Wu, C. (1994). Resilient and vulnerable adolescents. In R. D. Conger \& G. H. Elder (Eds.), Families in troubled times (pp. 223-234). Hawthorne, NY: Aldine de Gruyter.

Sorokin, P., \& Zimmerman, C. C. (1929). Principles of rural-urban sociology. New York: Henry Holt.

Steinberg, L. D., \& Dornbusch, S. M. (1991). Negative correlates of part-time employment during adolescence: Replication and elaboration. Developmental Psychology, 27, 304-313.

Sundberg, N. D., Tyler, L. E., \& Poole, M. E. (1984). Decade differences in rural adolescents' views of life possibilities. Journal of Youth and Adolescence, 13, 45-56.

Swaim, P. (1995). Adapting to economic change: The case of displaced workers. In L. 
J. Beaulieu \& D. Mulkey (Eds.), Investing in people: The human capital needs of rural America (pp. 213-234). Boulder, CO: Westview.

Swaim, P., \& Teixera, R. A. (1991). Education and training policy: Skill upgrading options for the rural workforce. In Education and rural economic development: Strategies for the 1990s (Economic Research Service, Staff Report No. AGES 9153, pp. 122162). Washington, DC: U.S. Department of Agriculture, Agriculture and Rural Economy Division.

Swanson, L. L., \& Butler, M. A. (1988). Human resource base of rural economies. In D. L. Brown, J. N. Reid, H. Bluestone, D. A. McGranahan, \& S. M. Mazie (Eds.), Rural economic development in the 1980s: Prospects for the future (RDRR-69, pp. 159-179). Washington, DC: U.S. Department of Agriculture, Economic Research Service.

Trowbridge, N., Trowbridge, L., \& Trowbridge, L. (1972). Self-concept and socioeconomic status. Child Study Journal, 2, 123-142.

Truesdell, L. E. (1949). The development of the urban-rural classification in the United States: 1874 to 1949 . Current Populations Reports, Population Characteristics, P-23, $1-16$.

U.S. Census Bureau. (1992). 1990 census of population: General population characteristics. Washington, DC: Government Printing Office.

U.S. Department of Agriculture. (1993). Rural conditions and trends, 4(3). Washington, DC: Economic Research Service, U.S. Department of Agriculture.

Wenk, D., \& Hardesty, C. (1993). The effects of rural-to-urban migration on the poverty status of youth in the 1980s. Rural Sociology, 58(1), 76-92.

White, L. K., Brinkerhoff, D. B. (1981). The sexual division of labor: Evidence from childhood. Social Forces, 60(1), 170-181.

William T. Grant Foundation Commission on Work, Family, and Citizenship. (1988). The forgotten half: Pathways to success for America's youth and young families. Washington, DC: Author.

Willits, F. K., \& Bealer, R. C. (1963). The utility of residence for differentiating social conservation in rural youth. Rural Sociology, 28(1), 70-80.

Willits, F. K., \& Bealer, R. C. (1967). An evaluation of a composite definition of "rurality." Rural Sociology, 32, 163-177.

Wilson, S. M., \& Peterson, G. W. (1988). Life satisfaction among young adults from rural families. Family Relations, 37, 84-91.

Wirth, L. (1938). Urbanism as a way of life. American Journal of Sociology, 44, 18.

Zelizer, V. A. R. (1985). Pricing the priceless child: The changing social value of children. New York: Basic Books. 